Research Article

\title{
Evaluation and Analysis of Dam Operating Status Using One Clock-Synchronized Dual-Antenna Receiver
}

\author{
Yunlong Zhang $\mathbb{D}^{\mathrm{D}},{ }^{1}$ Songlin Yang, ${ }^{1}$ Jiankun Liu, ${ }^{1}$ Dongwei Qiu $\mathbb{D}^{2},{ }^{2}$ Xiaoyan Luo, ${ }^{3}$ \\ and Jianhong Fang ${ }^{4}$ \\ ${ }^{1}$ School of Civil Engineering, Beijing Jiaotong University, Beijing 100044, China \\ ${ }^{2}$ School of Geomatics and Urban Spatial Informatics, Beijing University of Civil Engineering and Architecture, Beijing 100044, China \\ ${ }^{3}$ Beijing Key Laboratory of Urban Spatial Information Engineering, Beijing Institute of Surveying and Mapping, \\ Beijing 100038, China \\ ${ }^{4}$ Qinghai Research Institute of Transportation, Xining 810001, China
}

Correspondence should be addressed to Yunlong Zhang; 13115311@bjtu.edu.cn and Dongwei Qiu; qiudw@bucea.edu.cn

Received 18 September 2017; Revised 26 January 2018; Accepted 4 March 2018; Published 22 April 2018

Academic Editor: Yee-wen Yen

Copyright @ 2018 Yunlong Zhang et al. This is an open access article distributed under the Creative Commons Attribution License, which permits unrestricted use, distribution, and reproduction in any medium, provided the original work is properly cited.

Higher monitoring cost is the main limiting factor in the application of geodetic receivers in dam deformation monitoring, as the number of receivers applied in one dam is always too large. In this paper, an improved GNSS monitoring scheme is proposed. Firstly, three-dimensional finite element model is built to simulate the main deformation part of the dam, and only one clocksynchronized dual-antenna receiver is used to set the reference and monitoring stations; then, the dam displacement warning standard is determined based on the relationship between the corresponding surface displacement and safety factor of the different mechanical parameter combination; finally, through BDS/GPS dam deformation monitoring system for Lijiaxia in China, the operating status of dam is evaluated. Through comparative analysis, it is found that the scheme is feasible.

\section{Introduction}

External deformation is an important monitoring part of reservoir dam, which can provide important data for dam safety operation and deformation mechanism analysis [1,2]. Accuracy, cost, and automation are the important factors that need to be considered in dam deformation monitoring. The traditional monitoring methods, such as total station, level, and theodolite, did not allow the real-time, continuous and automatic monitoring of dam [3]; GNSS (Global Navigation Satellite System) has been used for the surface deformation monitoring of the engineering structure based on its highprecision and high-automation characteristics [4-6] but with higher cost of geodetic receivers severely limiting its application in the dam deformation monitoring.

Multiantenna method is proposed for reducing the monitoring cost. He et al. conducted a remote-controlled GPS monitoring system using GPS multiantenna technology and General Packet Radio Service (GPRS) wireless data communication to monitor the dam deformation and steep slope movement for reducing cost in large projects [7-9]. However, the multiantenna method is not multiantenna clock-synchronized technology in the true sense. The monitoring needs continuous switch between antennas using microwave switches, causing phase cycle-slip error; moreover, each switch needs reinitialization, and single-epoch positioning is not available.

GNSS deformation monitoring integrated system can realize the continuous and automatic monitoring of the dam external deformation. Jiang et al. developed the GPS deformation monitoring system of reservoir dam and achieve the automated, high-precision dam deformation monitoring [10-13]. Unfortunately, the cost of the system is also too high, caused by the geodetic receivers.

Clock-synchronized dual-antenna receivers are totally diverse from the geodetic receivers, which are very expensive (>\$4600) and cumbersome ( $>6 \mathrm{~kg})$. Meanwhile, not like the traditional GNSS multiantenna technology, the dual- 
channel RF front-end and digital correlator share the same clock module, avoiding cycle slip error and realizing singleepoch positioning, owing to electronic component reduction of clock-synchronized dual-antenna receivers, the newgeneration N71JN from Shanghai Huace Navigation Technology Ltd. in Figure 1, which has low cost $(<\$ 1565)$ and light $(<3.6 \mathrm{~kg})$. Moreover, most of the dam GNSS surface monitoring schemes are unreasonable, and GNSS monitoring station overabundance results in tremendous waste of equipment resources $[4,6,10,12,14]$.

In this paper, three-dimensional finite element model (TFEM) of Lijiaxia Dam is built in order to analyze the main deformation area and extract the critical point of Lijiaxia Dam. The stage early warning standard for dam deformation is determined based on the relationship between displacement and safety factors corresponding to different parameter combination. Through BDS (BeiDou Navigation Satellite System)/GPS (Global Positioning System) dam deformation monitoring system (DDMS) of Lijiaxia Hydropower Station and BJMonitor software using embedded robust weighting based on moving window (RWMW) developed independently, the operation status of the dam is evaluated based on the warning standard and the displacement measured with only one clock-synchronized dual-antenna receiver, to verify the effectiveness of the monitoring scheme.

\section{Warning Criteria and Model}

2.1. TFEM of Lijiaxia Dam. Lijiaxia Hydropower Station is a large hydropower project on the Yellow River upstream, and the dam is a double-curvature arch dam with three-centered arc. The dam height is $155 \mathrm{~m}$, the top elevation of the dam is $2185 \mathrm{~m}$, and the dam top width is $8 \mathrm{~m}$.

In order to ensure the dam operating safety, the number of GNSS observation stations set on the crest is usually larger than three, resulting in a great waste of equipment resources. In theory, as long as the main deformation area of the dam is determined, the dam operation status can be evaluated based on displacement data measured with only one clocksynchronized dual-antenna receiver. To minimize the cost and make more reasonable use of GNSS equipment, this paper proposes that TFEM is built by using the ANSYS software to predict the deformation of the Lijiaxia Dam. The Drucker-Prager criterion is adopted for numerical simulation analysis; according to the predicting displacement and the stress condition, the primary deformation area is determined [15-18]. In order to simplify the calculation, the structural materials are mainly divided into three categories: good rock mass, weak rock mass, and concrete. Through the relevant literature, the physical and mechanical parameters are determined and shown in Table 1, the concrete temperature expansion coefficient is set to $1 \times 10^{-5} /{ }^{\circ} \mathrm{C}$ [19]. As shown in Figure 2, the geometric dimensions of TFEM are $480 \mathrm{~m} \times 700 \mathrm{~m} \times 305 \mathrm{~m}$ (along the river, to cross the river, and to height difference). The upper surface is unconstrained, and both sides of the dam and the dam bottom are normal constraint. The upstream water level is set to the normal water level $2180 \mathrm{~m}$ and the downstream water level $2050 \mathrm{~m}$. The upstream and downstream interception boundaries are treated with impervious boundaries, as well as the boundaries between the left and right banks are treated with known heads, which are extrapolated based on the long-term measured data of observation holes in groundwater [20].

2.2. Main Deformation Dam Section. Compared to the upstream, the water depth downstream is lower, generally at around $30 \mathrm{~m}$ and has less influence on the dam deformation, thus only the upstream water weight, water pressure, and dam deadweight are considered in the numerical calculation of each dam segment displacement. Combined with the field temperature and upstream water depth data which is considered in the numerical calculation of each dam segment displacement, TFEM is established to calculate the deformation of the dam. As shown in Figure 3, the dam is divided into 20 sections, and the displacement information of critical point of each dam section is extracted. According to the numerical simulation result in the right part of Figure 3, the main forced location of the dam is determined. Figure 4 shows that the numerical simulation deformation of each dam section is proportional to its mean water depth upstream in 2011, and the correlation coefficient reaches 0.99 . Due to the maximum water depth, the relative displacement of the critical point at number 11 dam section to the number 1 dam section is maximal. The relative deformation is about $13 \mathrm{~mm}$, that is, the critical point of the number 11 dam can obviously reflect the dam operation state as the unique GNSS monitoring point, to make real-time monitoring of dam operating status.

Compared with manual measurement methods, the surveying robot is widely applied in dam deformation monitoring field, and relevant scholars have verified the surveying robot has the high precision [3]. The local independent coordinate system was established in Figure 3; the TM30 total station was adopted to survey the critical point coordinate at dam section numbers 1 to 20 ; the equal interval coordinates per day in 2011 were selected to calculate the displacement of other dam sections relative to dam section number 1 in Figure 5; and the relative displacement at dam section 11 is the largest in most time, approximately up to $10 \mathrm{~mm}$. Strictly speaking, the structural materials of Lijiaxia Dam are not only three categories, and for simple numerical calculation, the model is just a simplified one; meanwhile, due to the impact of external observation conditions, such as wind, temperature, and atmospheric refraction, the surveying robot measurement error is inevitable, which can reach $0.6+1 \times 10^{-6} \cdot D \mathrm{~mm}$ ( $D$ represents ranging length, the unit is $\mathrm{km}$ ), so compared to the displacement measured by the surveying robot, the numerical simulation results have some deviation. However, the deviation is within acceptable limits, just about $3 \mathrm{~mm}$; thus, it is verified that determining the main deformation section based on the finite element model is effective.

2.3. Deformation Warning Criteria. It is important to make warning criteria of surface displacement for evaluating the operating status of engineering structure. To determine the displacement warning standard, Zhang et al. [21] designed 


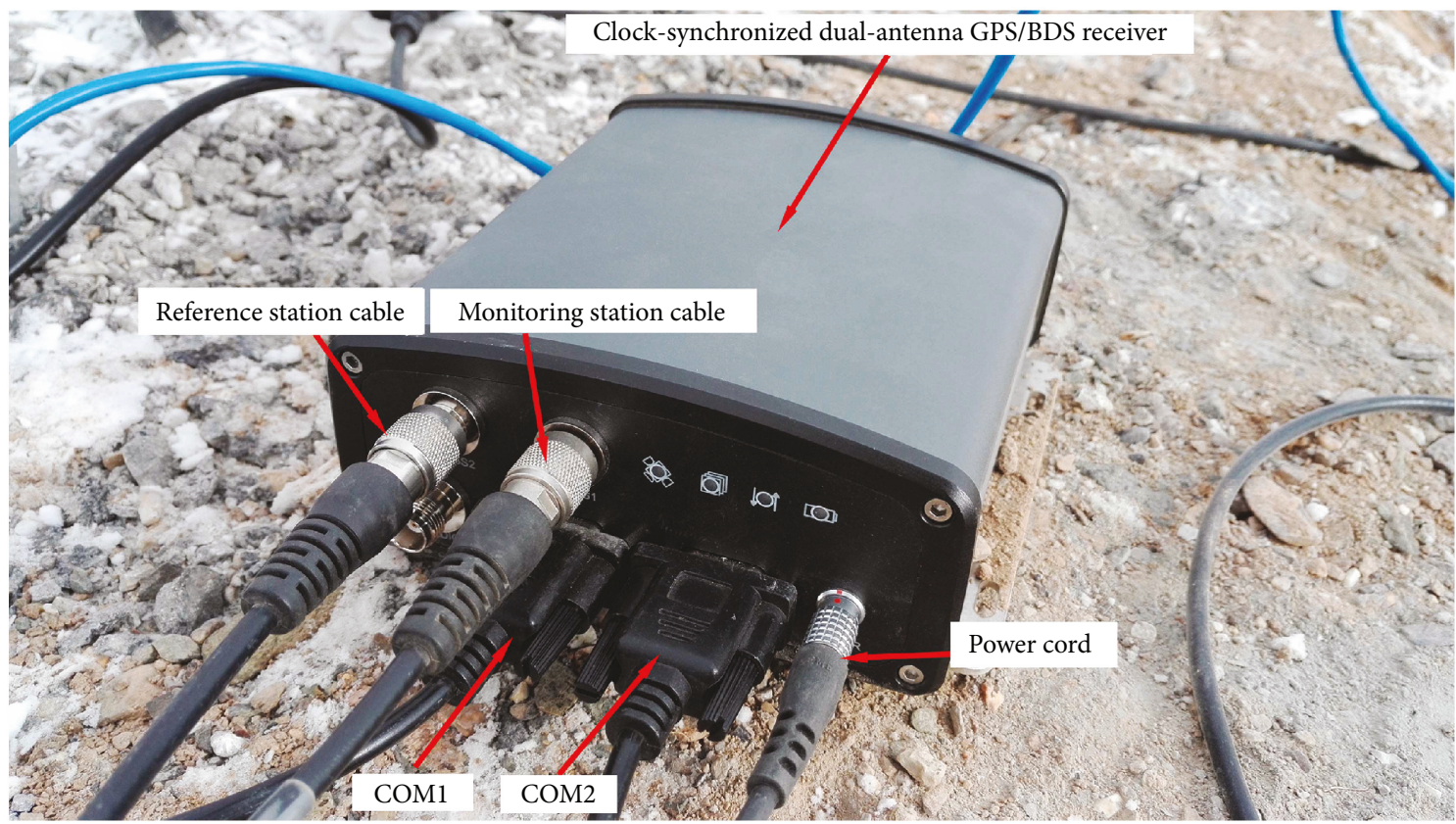

FIGURE 1: New generation of clock-synchronized dual-antenna receivers.

TABLE 1: Mechanical parameters of structural materials in Lijiaxia Dam.

\begin{tabular}{lccccc}
\hline Material & Elastic modulus $(\mathrm{GPa})$ & Cohesion $(\mathrm{MPa})$ & Position ratio & Appearance density $\left(\mathrm{t} / \mathrm{m}^{3}\right)$ & Friction angle $($ deg $)$ \\
\hline Good rock mass & 10 & 1.0 & 0.30 & $1 \times 10^{-5}$ & 32 \\
Weak rock mass & 8 & 0.9 & 0.30 & $1 \times 10^{-5}$ & 32 \\
Concrete & 30 & 2.5 & 0.18 & 2.4 & 54.9 \\
\hline
\end{tabular}

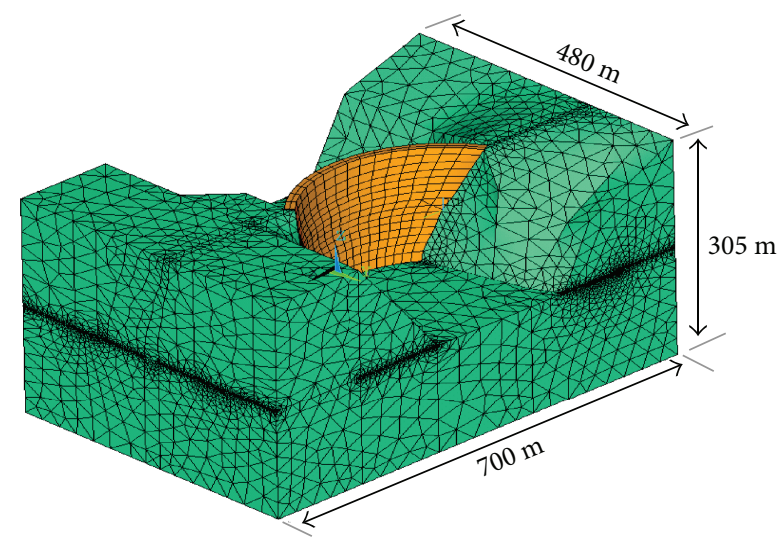

FIgUre 2: TFEM of Lijiaxia Dam.

the different combination in the value range of mechanical parameters to represent the impact on the slope stability by water level, temperature, and other factors and to calculate the critical point displacement and corresponding safety factor through the plastic analysis module of ANSYS. The method is also applicable to the Lijiaxia Dam, and the critical point at dam section 11 can also be chosen to determine warning criteria. Figure 6 shows the exponential function is used to fit the data of displacement and safety factor; after derivation calculus to the equation in the figure, the displacement trend can be predicted. In the right graph, points 1-4 are selected for which displacements are larger, where the corresponding displacement of point 1 is $15 \mathrm{~mm}$ (as the yellow alarm value) and the safety factor is 3 ; the displacement and safety factor at point 2 are $20 \mathrm{~mm}$ (as the orange alarm value) and 2.5, which at points 3 and 4 corresponding to $40 \mathrm{~mm}$ (as the red alarm value), 2 and $120 \mathrm{~mm}$, 1.8 , respectively. It can be seen that as the station of GNSS02 in Figure 3 up to the displacement at point 1, the dam is in the initial instability state; after the displacement at point 2 , the dam gets into the rapid instability state; after point 3 , the dam is in the accelerated instability state, and to reach point 4 , the dam is in the destruction of the collapse stage.

\section{DDMS for Lijiaxia Dam}

3.1. System Composition and Function. BJMonitor, PostgreSQL, and BDS/GPS data publishing management system are integrated in order to formulate DDMS. The communication system between host computer and receivers is held based on TCP/IP protocol, then data reception, processing, and storage are realized. Data publishing management system is connected with the database through .NET, including real-time data display, query, alarm, predictive analysis, and report generation function. The system architecture is shown in Figure 7. 


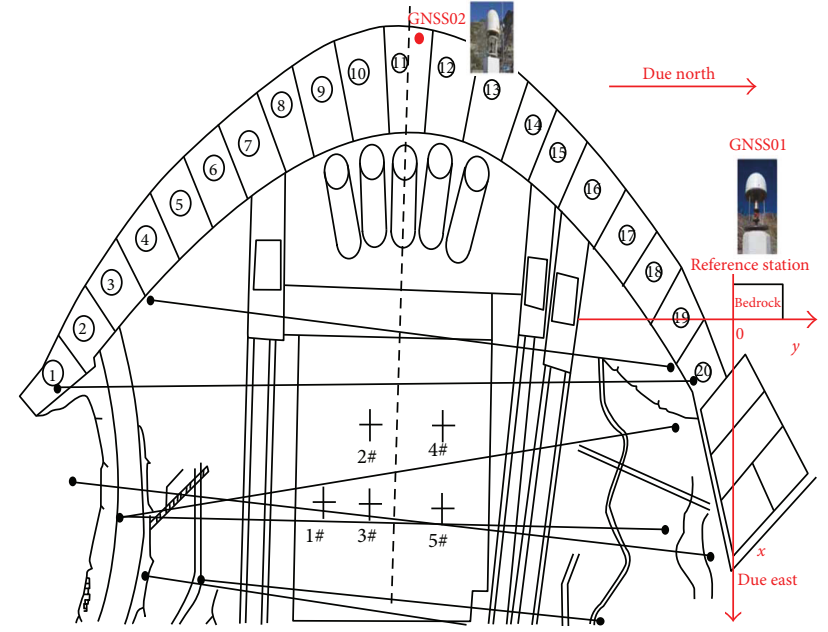

(a)

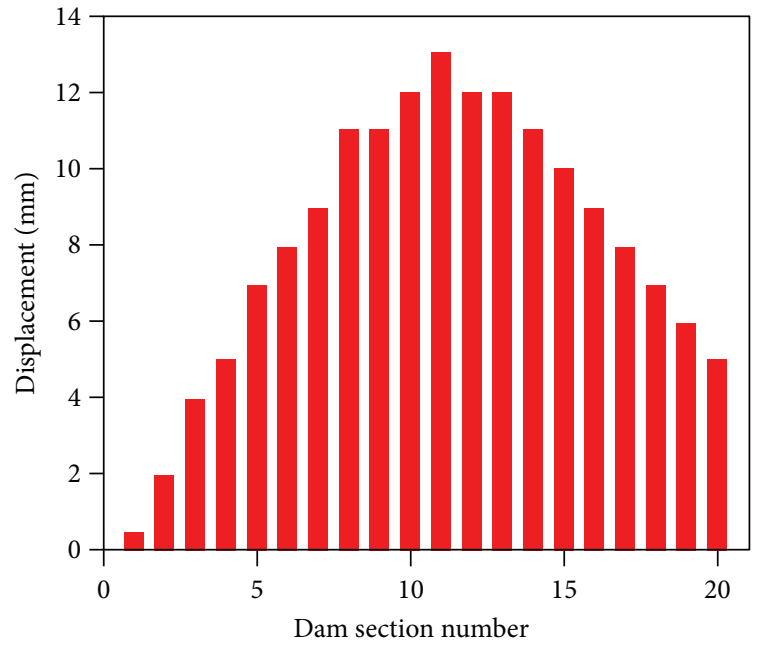

(b)

FIGURE 3: Numerical simulation deformation and monitoring point placement of the Lijiaxia Dam.

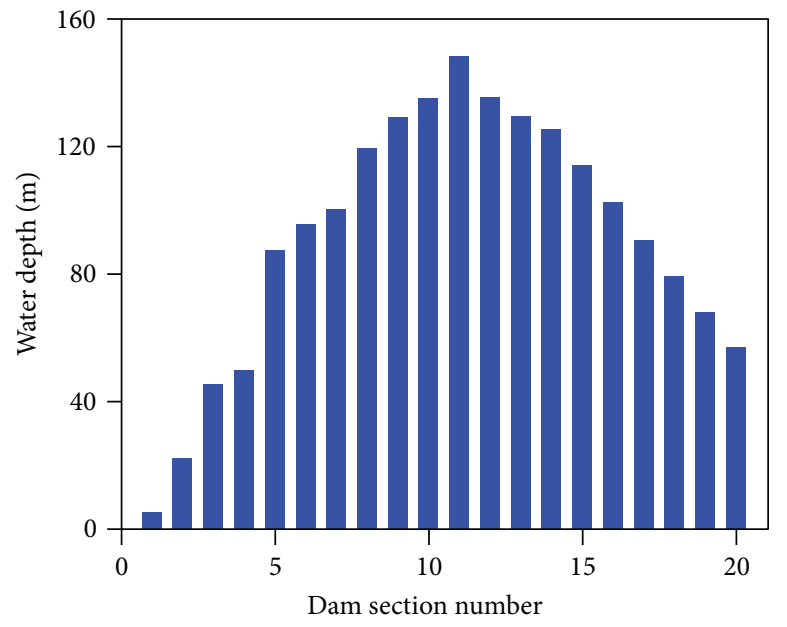

(a)

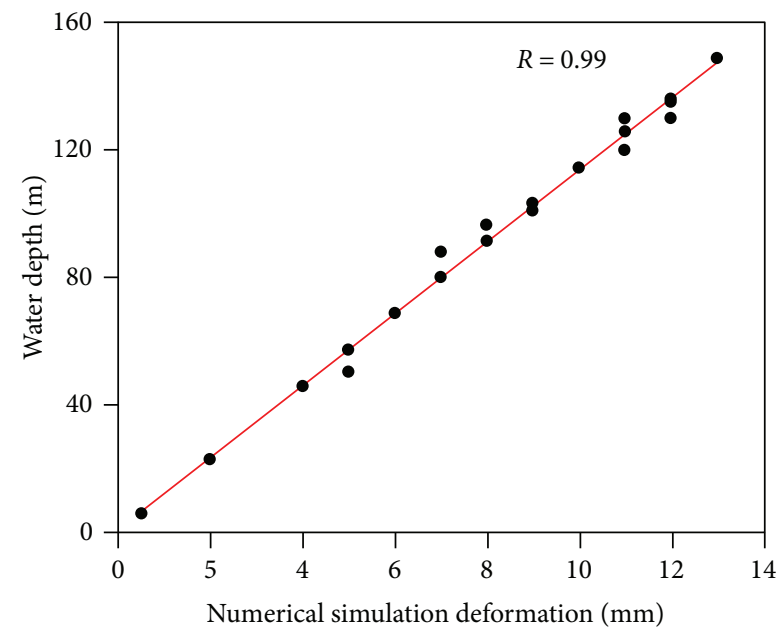

(b)

FIGURE 4: Mean water depth upstream in 2011 and relation between water depth and numerical simulation deformation.

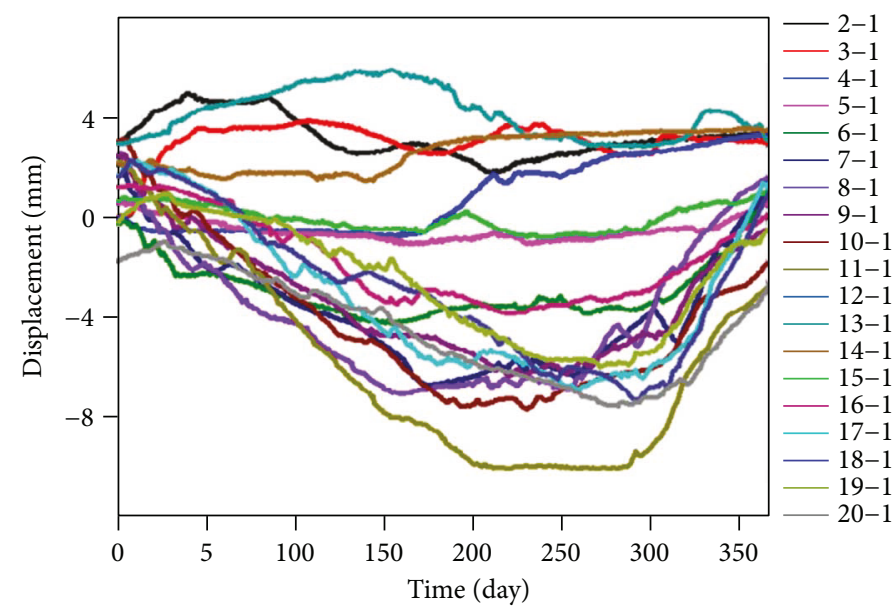

Figure 5: Displacement per day of the key point of each dam section relative to number 1 dam section in 2011. 

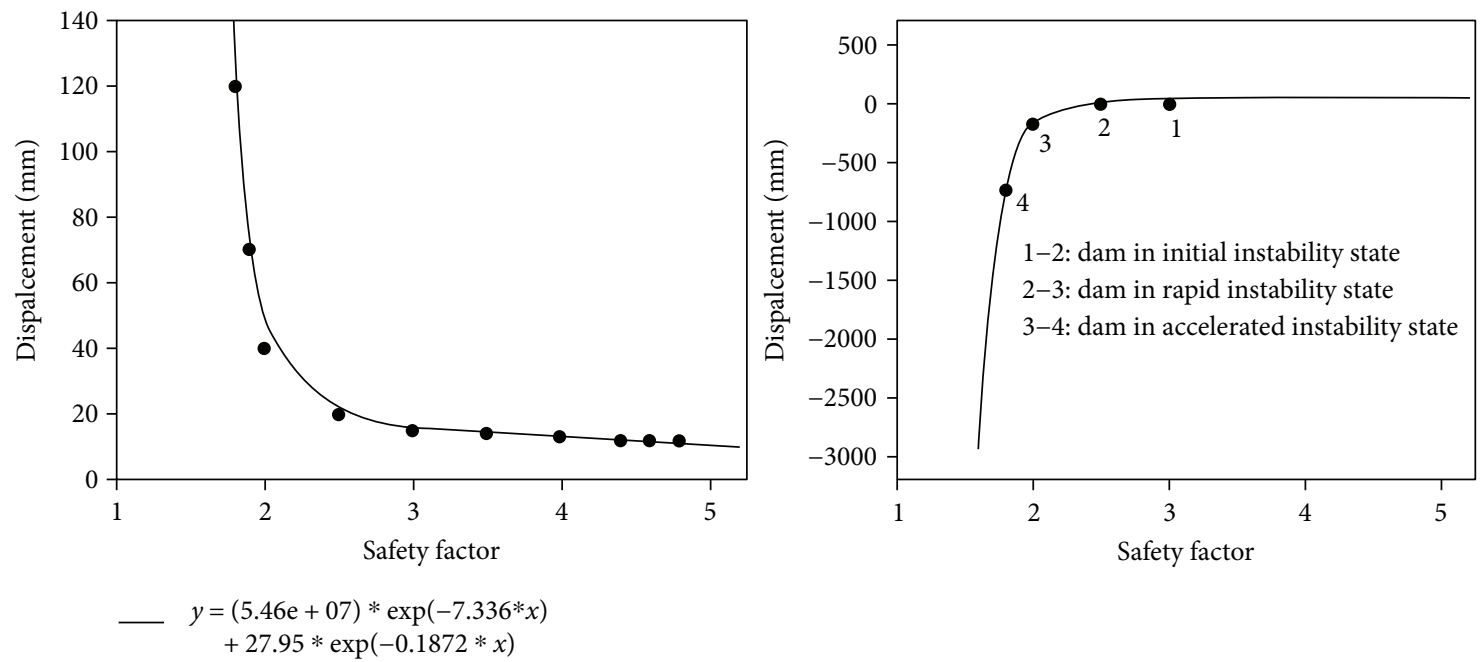

Figure 6: Relationship of the key point deformation and safety factor of the number 11 dam section.

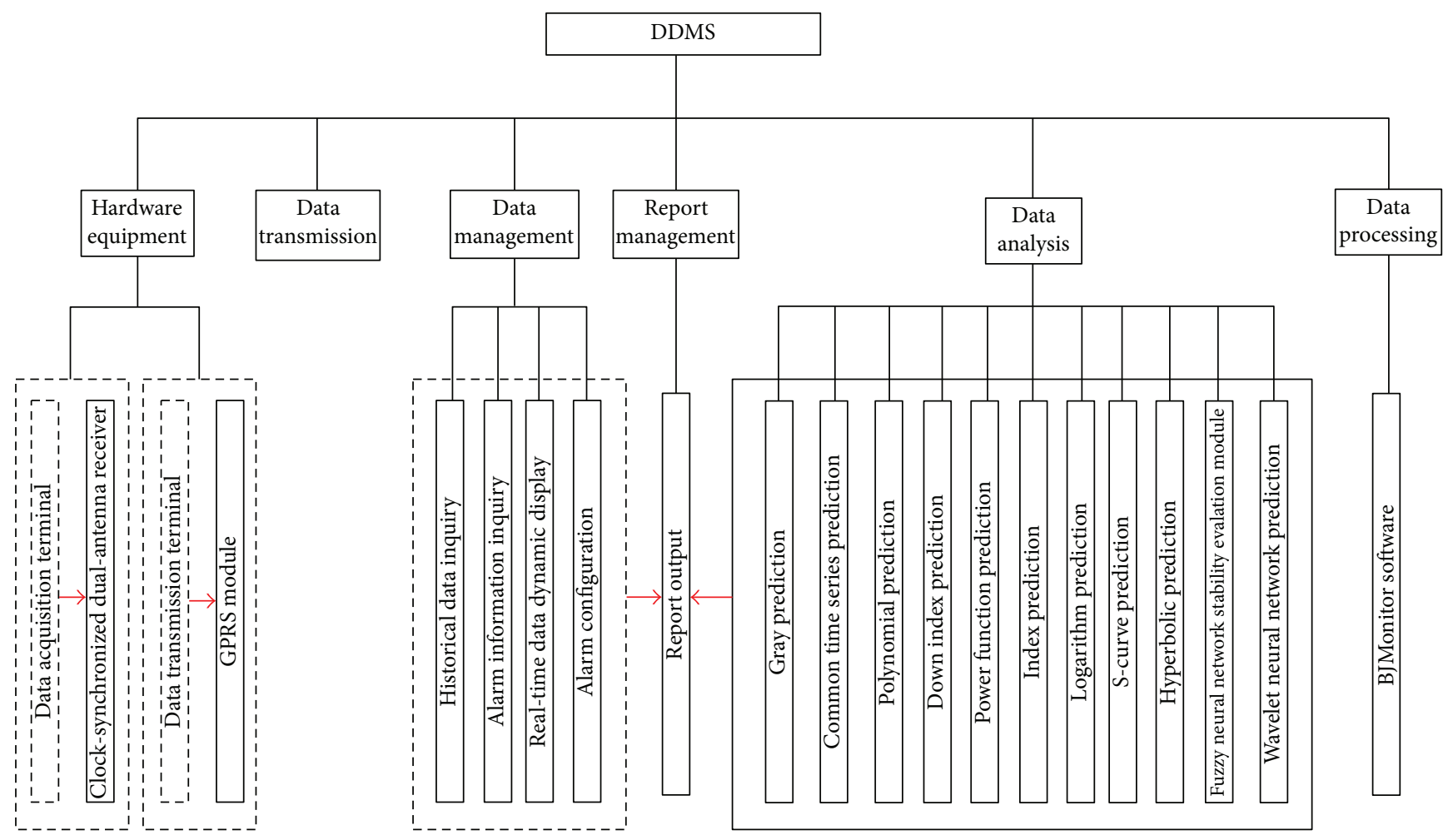

FIGURE 7: DDMS architecture.

3.2. Hardware Equipment. The hardware device mainly includes the data acquisition terminal, and the N71JN receiver system is adopted, consisting of the reference station antenna, the monitoring station antenna, and the clocksynchronized dual-antenna receiver. As shown in Figure 8, N71JN receiver composes of a dual-channel RF front-end, a dual-channel digital correlator, and a processor connected in order. The most prominent characteristic is that the clock signal is provided by the same clock module for the above components; moreover, the same processor is used to avoid a variety of hardware channel inconsistencies, and the reference and monitoring station antenna system have the common crystal oscillator, so compared with traditional geodetic receivers, the pseudorange and phase observations are more accurately extracted from the dual-channel digital correlator.

3.3. Data Transmission. BDS/GPS observation data is transferred to the GPRS module through the receiver ports COM1 and COM2 in Figure 1, then sent to the data 


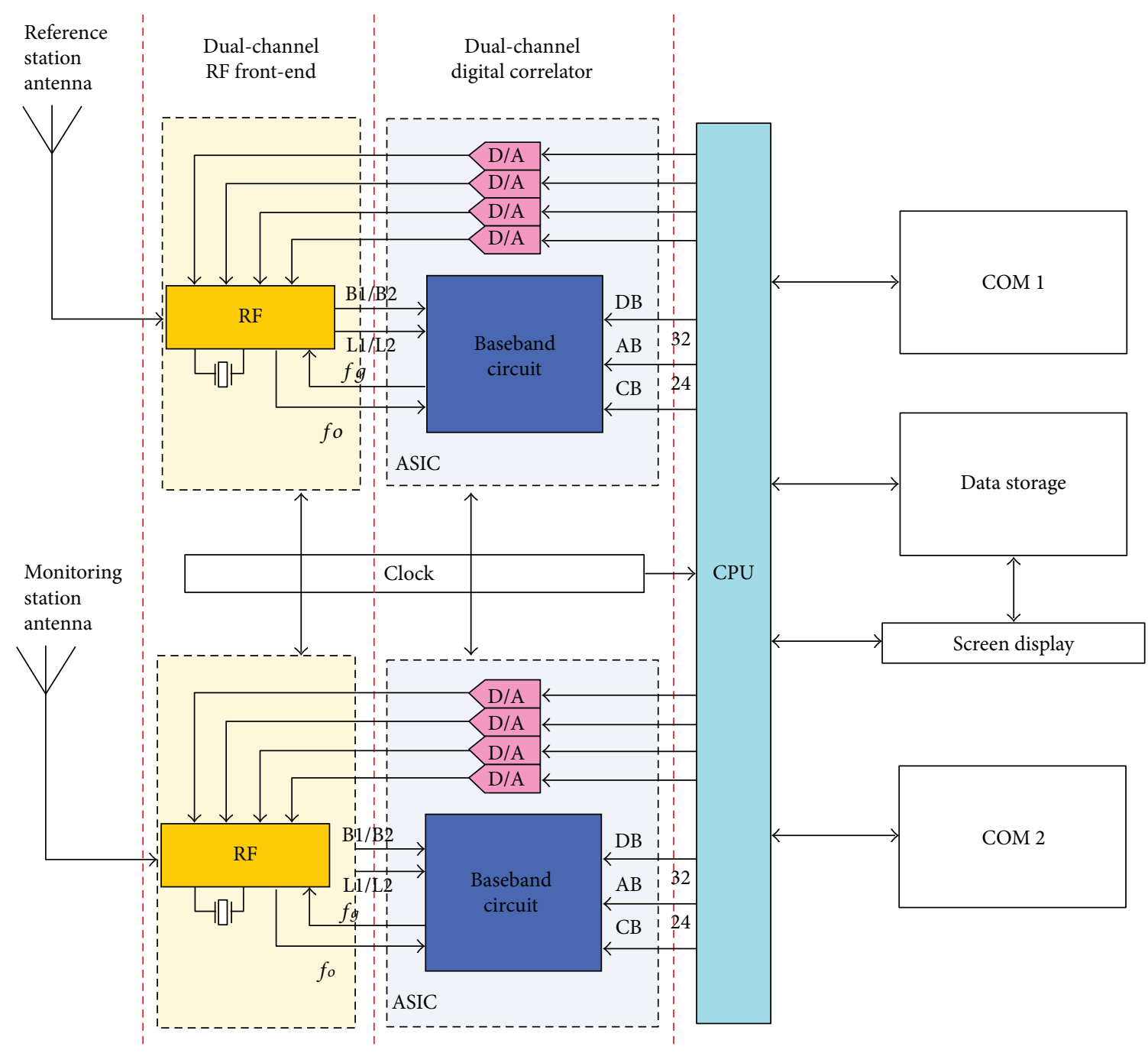

FIgURE 8: Architecture of N71JN hardware equipment.

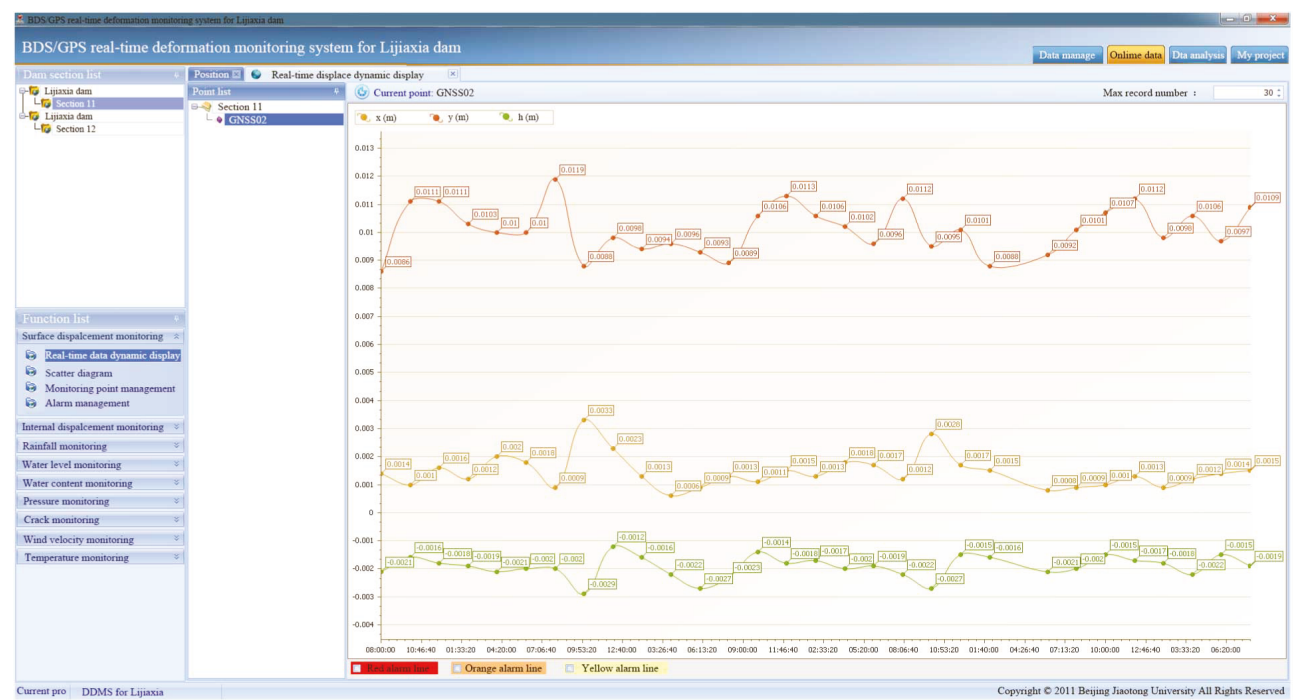

Figure 9: Data display in real time. 


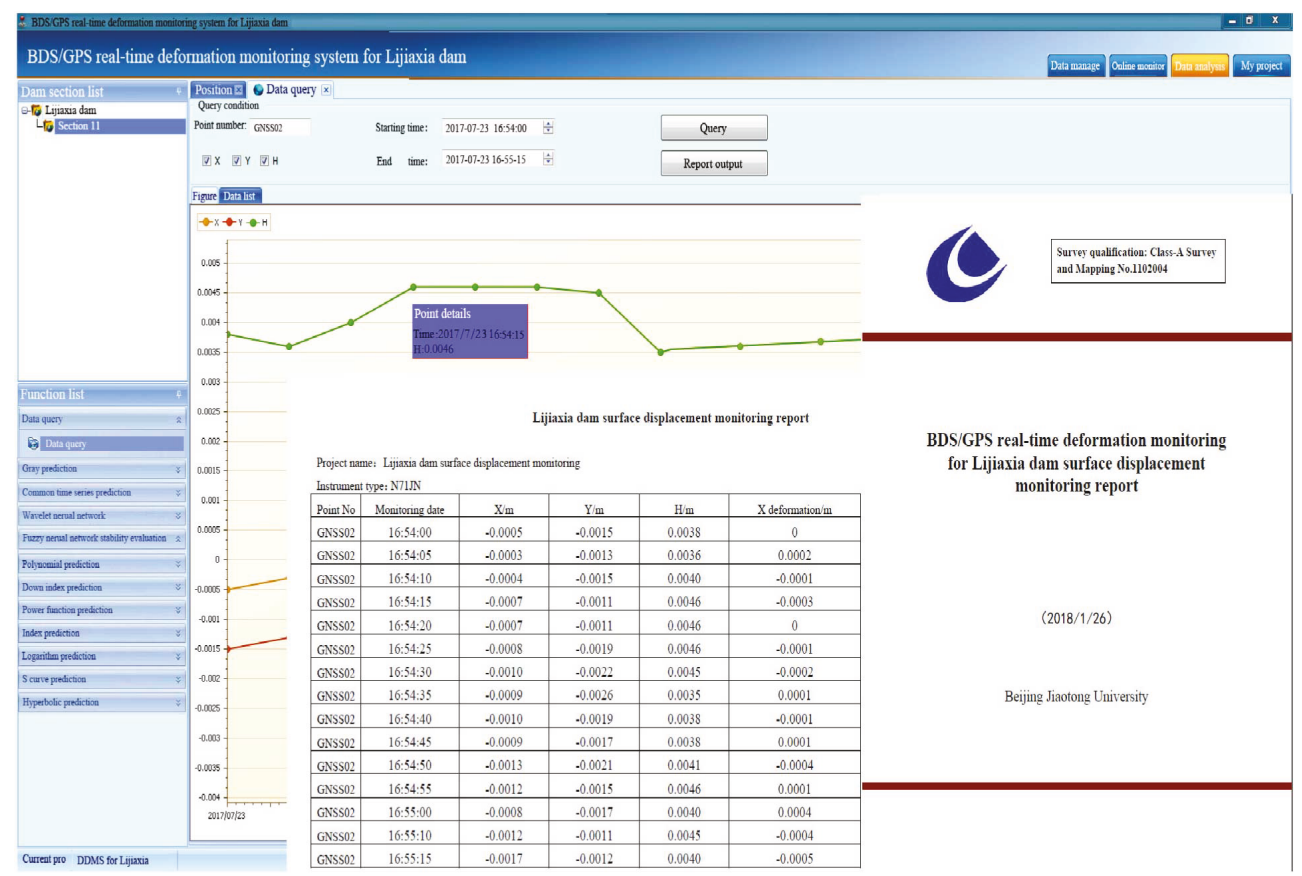

Figure 10: Data query and report generation.

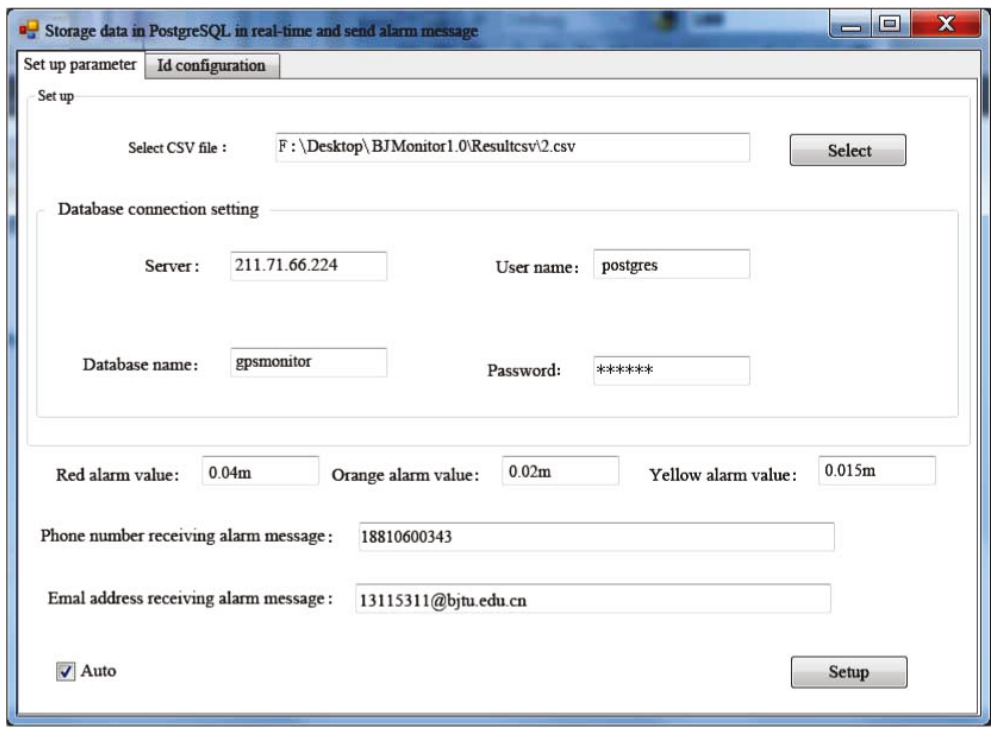

Figure 11: Data loader module in real time.

processing center by the GPRS module. The parameters need to be configured, including the server fixed IP address and port written into the GPRS module. Data transmission can be achieved between the GPRS module and server through the public network IP and port mapping program. For the central server has a fixed IP, the router can map the public network port to the corresponding ports in the local area network. GPRS is connected with the central public network IP port by the DNS server, and the wireless data communication between the GPRS module and server can be achieved [22].
3.4. Data Processing. BJMonitor is taken as data processing software, using embedded RWMW module. GNSS positioning accuracy is mainly affected by the error such as antenna, receiver and cable hardware delay, and multipath effects. In order to improve the estimation accuracy of observation noise variance, the moving window parameter can appropriately be increased properly, and the Helmert variance component estimated by introducing time-correlated forgetting factor is used to achieve the precise weight ratio between GPS and BDS observations; then, the history window data 


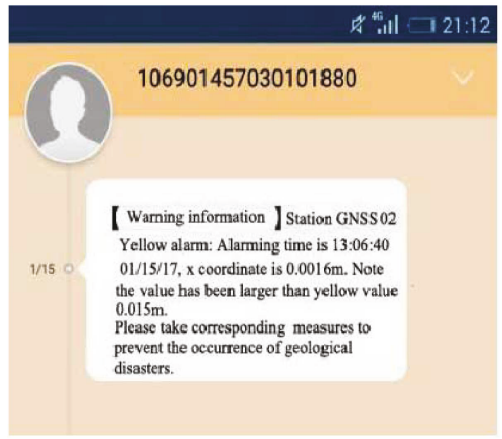

(a)

(b)

FIgURe 12: Short message and email alarm.

\begin{tabular}{|c|c|c|c|c|c|}
\hline & & \multicolumn{2}{|c|}{ Project-user correlation } & & \\
\hline & & ID & Project ID & & \\
\hline & & M_ID & $\begin{array}{l}\text { Management } \\
\text { ID } \\
\end{array}$ & & \\
\hline & & $\ldots$ & $\ldots$ & & \\
\hline & & $\cdots$ & $\cdots$ & & \\
\hline \multicolumn{2}{|c|}{ Project information table } & & & \multicolumn{2}{|c|}{ Manager information table } \\
\hline ID & Project ID & & & ID & Project ID \\
\hline M_unit & $\begin{array}{c}\text { Management } \\
\text { unit }\end{array}$ & & & M_name & Name \\
\hline Pro_name & Project name & & & M_phone & Phone \\
\hline Creator & Creator & & & M_email & Email \\
\hline Cre_time & Creating time & & & $\cdots$ & $\cdots$ \\
\hline \multicolumn{2}{|c|}{ Monitoring data table } & & & \multicolumn{2}{|c|}{ Alarm information table } \\
\hline ID & Project ID & & & ID & Project ID \\
\hline D_secid & $\begin{array}{c}\text { Dam section } \\
\text { ID }\end{array}$ & & & D_secid & $\begin{array}{c}\text { Dam section } \\
\text { ID }\end{array}$ \\
\hline P_name & Point name & & & P_name & Point name \\
\hline$x$ & $x$ coordinate & & & $x \_$alarm & $x$ alarm value \\
\hline$y$ & $y$ coordinate & & & $y \_$alarm & $y$ alarm value \\
\hline$h$ & $h$ coordinate & & & $h \_$alarm & $h$ alarm value \\
\hline
\end{tabular}

FIGURE 13: ER diagrams.

is used to improve the accuracy of observation variance at the current epoch by smoothing the noise; finally, the displacement detection with submillimeter accuracy can be achieved based on the KALMAN filter [23]. The specific calculation principle has been presented in literature 22 , so here, it is not described in detail again.

3.5. Data Management. Data management module mainly consists of data storage, real-time display, query, alarm information sending, and query and report generation functions and provides $\mathrm{C} / \mathrm{S}$ platform for managers to manage the monitoring data. As shown in Figures 9-12, the module can be used to query, display three-dimensional coordinate data in real-time, generate the corresponding report, store the data, and send the alarm short message and mail.

PostgreSQL is an open-source database; moreover, interactive interface is good; therefore, the system takes PostgreSQL as a data management platform, to store and 


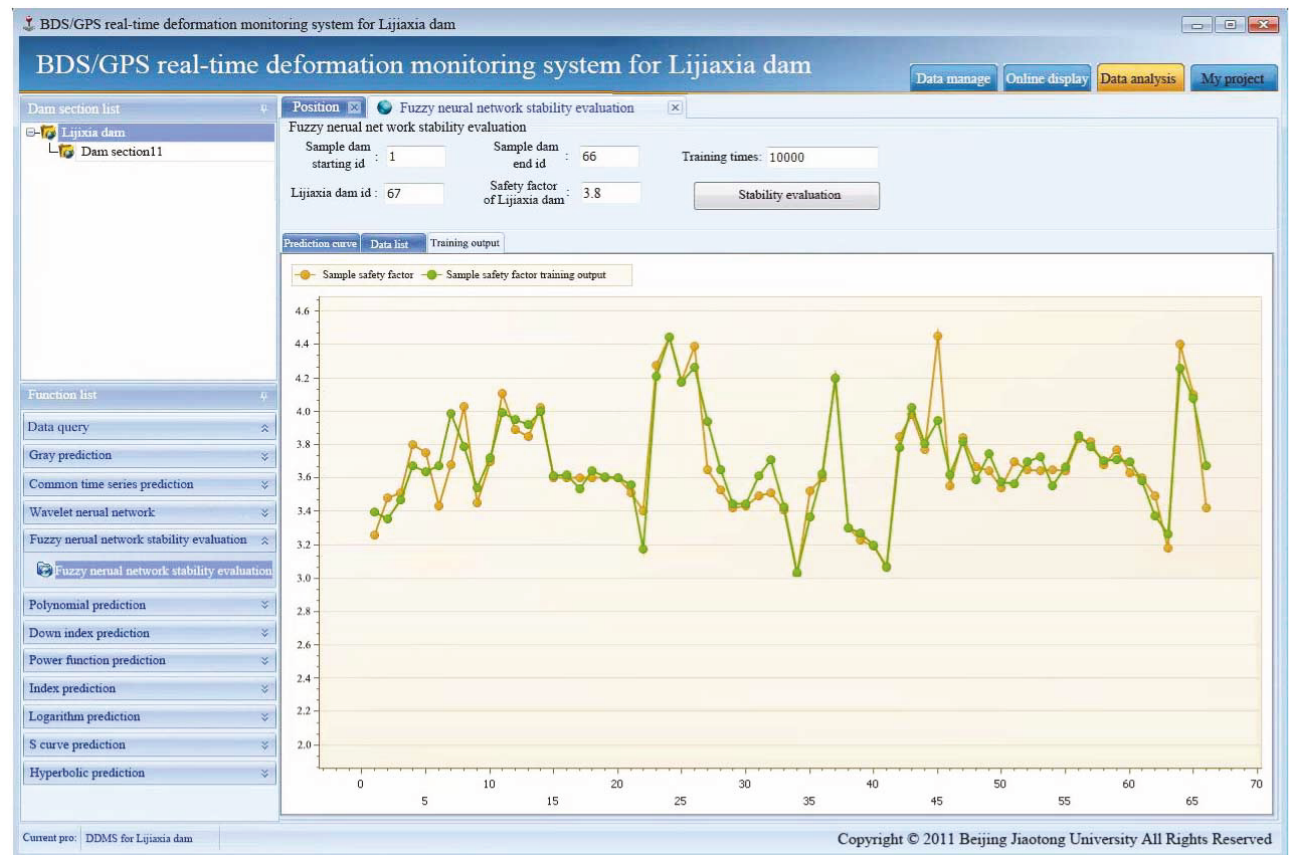

Figure 14: Forecast analysis module of Lijiaxia Dam.

manage three-dimensional coordinate data, alarm information, and so on. The core table ER is shown in Figure 13 [24].

3.6. Data Analysis. In view of the forecast analysis of the monitoring data of Lijiaxia Dam, DDMS was developed comprising the gray scale prediction, common time series, polynomial regression, and fuzzy neural network stability evaluation modules in Figure 14, training the sample data of the same kind of dam, to get the corresponding model of physical mechanics parameters and safety factor, then input the parameters obtained from the laboratory experiment, to calculate the safety factor of Lijiaxia Dam, and to evaluate the stability of the dam to test the reliability of the displacement warning standard [25-27].

\section{Lijiaxia Dam Stability Analysis}

The deformation mechanism of the dam is explored to ensure safety operation of the generator sets, as shown in Figure 3; according to the finite element numerical analysis results of Lijiaxia Dam and the precision requirement, the joint monitoring system was established based on GNSS and GeoMos surveying robot. The reference station of GNSS01 (the origin of local independent coordinate system) was set up on the bedrock near the dam, and the due east, due north, and due height were taken as the $x$-, $y$-, and $h$-axis; meanwhile, one monitoring station of GNSS02 was set up at dam section number 11 . The vertical axis concentric observation devices with eccentric prisms and two C220GR3D choke-ring antennas, connected with one clock-synchronized dual-antenna receiver, were installed at the two stations. The coordinates can be obtained through GNSS and total station TM30 at the same time, then the dam operating status is analyzed according to the displacement warning standard.

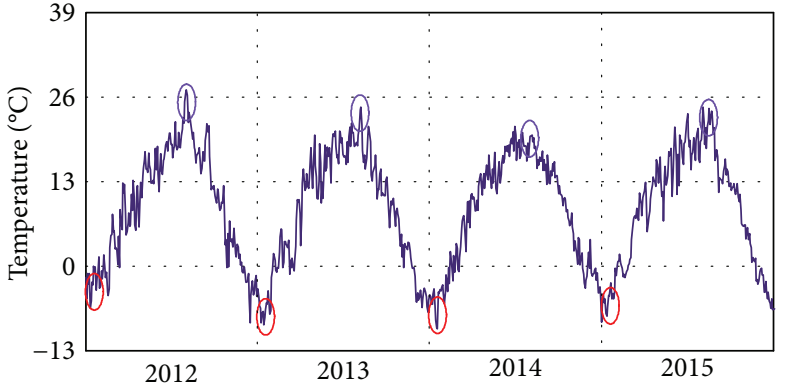

Figure 15: Temperature curve of Lijiaxia Dam during 2012-2015.

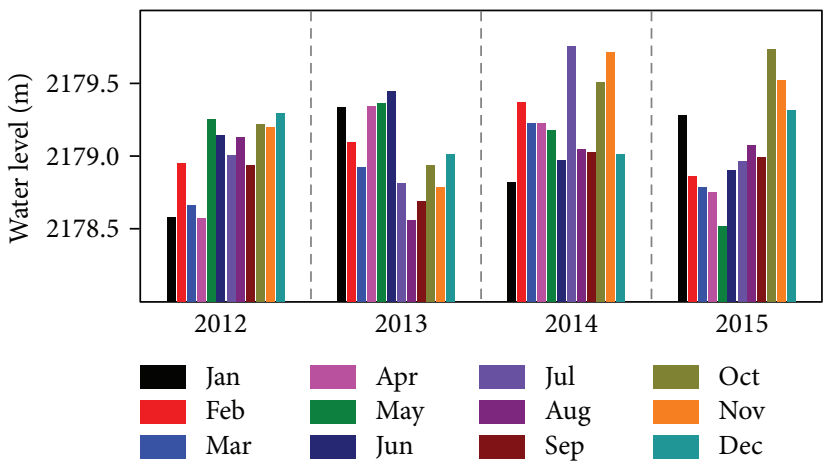

FIgURE 16: Statistics of the seasonal variations of the water level at dam section 11 during 2012-2015.

4.1. Deformation Law Analysis. As shown in Figure 3, the dam section number 11 is located in the middle of Lijiaxia arch dam, and it is the main position to undertake the pressures from landslides of both sides and water, which 

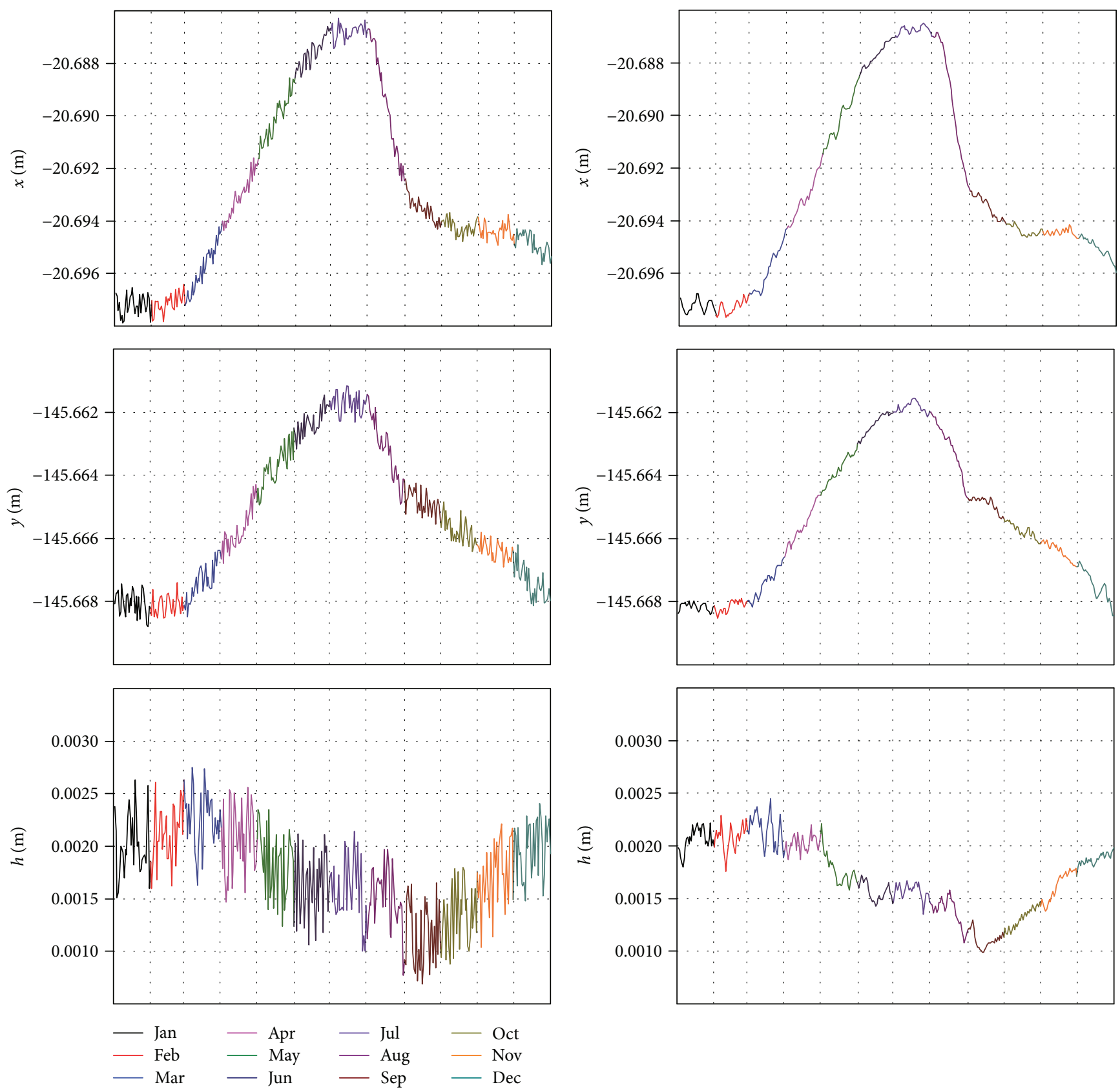

Figure 17: Coordinate series of station, GNSS02, at dam section 11, using the RWMW in 2015 (the left figures correspond to moving windows of $1 \mathrm{~h}$; the right figures correspond to moving windows of $2 \mathrm{~h}$ ).

is related to the safety operations of all the generators in the dam. And also, to analyze the influencing factors of Lijiaxia arch dam deformation and explore the availability of RWMW, the coordinate time series of station GNSS02 are emphatically analyzed.

To analyze the seasonal variation law of the data conveniently, the equal interval sampling ( 1 day) is adopted due to the large amount of data in real-time sampling (sampling interval is $5 \mathrm{~s}$ ). Figure 15 shows that the marked red circle represents the minimum temperature, and the marked purple circle represents the maximum temperature. The maximum temperature difference can reach $36^{\circ} \mathrm{C}$ between January and July. In the comparative analysis of
Figures 15-18, the dam absolute deformation is mainly caused by the seasonal temperature change. Since the seasonal water level of number 11 section during 2012 2015 changes slightly, the deformation has no obvious correlation with water level. Thus, the temperature seasonal change is the main factor for causing the dam deformation.

To study the main direction of dam deformation, the observation data in 2015 is selected for analysis. As shown in the right part of Figure 17, the moving window parameter can be appropriately increased to two hours; time forgetting factor is introduced, and then the history window data is used to improve the accuracy of observation variance at the current epoch by smoothing the noises, to achieve high- 


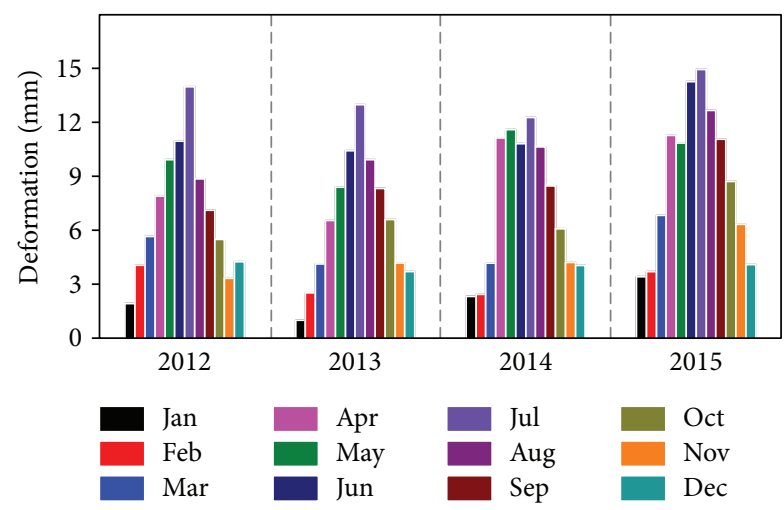

FIGURE 18: Seasonal deformation of station, GNSS02, at dam section 11, using the TM30, during 2012-2015.

precision positioning [23]. Due to both ends of dam arch that are pinned down by the mountains, which have very limited space of moving to the both banks and due height, and the arch dam expands on heating and contracts on cooling, Figure 17 shows it can only move upstream and downstream and can hardly move to both sides of the river. When the temperature reached the highest in July 2015, the arch dam moved upstream (due east), and the creep at station GNSS02 reached the maximum value of the coordinate, which was $-20.6875 \mathrm{~m}$. The dam body moved downstream (due west) in January 2015, and the creep reached the minimum value of the coordinates, which was $-20.6975 \mathrm{~m}$; its displacement was around $10 \mathrm{~mm}$. However, the seasonal temperature variation had little influence on both sides of the dam body, and the creep in due north reached the maximum value of the coordinates in July 2015, which was $-145.6625 \mathrm{~m}$; meanwhile, the creep in due south direction reached the minimum value of $-145.6678 \mathrm{~m}$; its displacement was around $5.3 \mathrm{~mm}$. Due height direction was barely influenced, and the coordinate was fluctuated within $1 \mathrm{~mm}$. The total displacement of January and July was $11.3 \mathrm{~mm}$, which was in accordance with the result obtained through TM30 presented in Figure 18; moreover, it is further explained that the RWMW algorithm is suitable for arch dam monitoring of Lijiaxia Hydropower Station with creep characteristics. According to the displacement warning standard, the displacement was less than $15 \mathrm{~mm}$, and the dam was in stable state. The safety function of the dam was predicted by the fuzzy neural network model according to the physical and mechanical parameters obtained from the relative literature [25]. Figure 14 shows the safety factor was 3.8 , larger than 3 , and it is further proved that the displacement warning criteria was effective.

\section{Conclusion}

The results of this research show that the proposed monitoring scheme to evaluate and analyze the operating status of Lijiaxia Dam using one clock-synchronized dual-antenna receiver is feasible. There are six conclusions as follows from the completed work:

(1) According to TFEM numerical simulation of Lijiaxia Dam, the main bearing part is considered as the GNSS monitoring station, and one clock-synchronized dual-antenna receiver is used to evaluate the dam operation status, one antenna as the reference station and the other as the monitoring station, greatly reducing the monitoring cost.

(2) TFEM is simplified, and the relationship between the safety factor of the dam and the critical point displacement is obtained based on different physical and mechanical parameter combination. The displacement warning criteria is established, and the validity of the standard is verified by the fuzzy neural network model.

(3) BJMonitor, PostgreSQL, and BDS/GPS data publishing management system are integrated to formulate DDMS, consisting of real-time dynamic display, query data, report generation, forecasting, and early warning functions. Through the longtime application in Lijiaxia Dam, the stability of the DDMS system is verified; moreover, it can provide technical support and basis for the similar engineering structure.

(4) Combined with the example of Lijiaxia Dam monitoring project, it is proved that the RWMW algorithm is suitable for the structure with creep characteristics, and the operation status of the dam is evaluated through the displacement warning criteria, and the effectiveness of the monitoring scheme is further verified.

(5) Through the numerical simulation result and water depth data, the relative displacement to number 1 dam section is proportion to water pressure, and the water depth of the number 11 section is highest; thus, the relative displacement at the center section to number 1 dam section is the largest.

(6) The water level of number 11 dam section almost maintains unchanged during 2012-2015, and the absolute deformation changes with temperature seasonal variations; thus, the temperature is the main influence on the absolute deformation of Lijiaxia Dam. Moreover, both ends of the dam arch are pinned down by the mountains, and the space of moving to both ends and due height is limited; the absolute deformation of number 11 dam section in the upstream and downstream direction is largest, both ends smaller, due height smallest.

This paper provides a new idea for dam monitoring of hydropower stations, greatly reducing the cost of equipment. Whether the monitoring scheme is applicable to other similar structures remains to be further validated.

\section{Conflicts of Interest}

The authors declare that they have no competing interests. 


\section{Acknowledgments}

This research was supported by the National Key R\&D Program of China (no. 2017YFB0503700) and Beijing Key Laboratory of Urban Spatial Information Engineering under Grant no. 2016101.

\section{References}

[1] J. Wang and C. C. Zhang, "Deformation monitoring of earth-rock dams based on three-dimensional laser scanning technology," Chinese Journal of Geotechnical Engineering, vol. 36, no. 12, pp. 2345-2350, 2014.

[2] D. González-Aguilera, J. Gómez-Lahoz, and J. Sánchez, “A new approach for structural monitoring of large dams with a three-dimensional laser scanner," Sensors, vol. 8, no. 12, pp. 5866-5883, 2008.

[3] C. O. Yigit, S. Alcay, and A. Ceylan, "Displacement response of a concrete arch dam to seasonal temperature fluctuations and reservoir level rise during the first filling period: evidence from geodetic data," Geomatics, Natural Hazards and Risk, vol. 7, no. 4, pp. 1489-1505, 2015.

[4] D. Galán-Martín, M. Marchamalo-Sacristán, R. MartínezMarín, and J. A. Sánchez-Sobrino, "Geomatics applied to dam safety DGPS real time monitoring," International Journal of Civil Engineering, vol. 11, no. 2, pp. 134-141, 2013.

[5] Y. Kalkan, L. V. Potts, and S. Bilgi, "Assessment of vertical deformation of the atatürk dam using geodetic observations," Journal of Surveying Engineering, vol. 142, no. 2, article 04015011, 2016.

[6] Y. Kalkan, "Geodetic deformation monitoring of Ataturk Dam in Turkey," Arabian Journal of Geosciences, vol. 7, no. 1, pp. 397-405, 2014.

[7] X. He, D. Jia, and W. Sang, "Monitoring steep slope movement at Xiaowan Dam with GPS multi-antenna method," Survey Review, vol. 43, no. 323, pp. 462-471, 2013.

[8] X. He, G. Yang, X. Ding, and Y. Chen, "Application and evaluation of a GPS multi-antenna system for dam deformation monitoring," Earth, Planets and Space, vol. 56, no. 11, pp. 1035-1039, 2004.

[9] X. L. Ding, Y. Q. Chen, D. F. Zhu et al., "Slope monitoring using GPS," GPS World, vol. 11, no. 3, p. 52, 2000.

[10] W. P. Jiang, H. F. Liu, W. K. Liu et al., "CORS development for Xilongchi Dam deformation monitoring," Geomatics and Information Science of Wuhan University, vol. 37, no. 8, pp. 949-952, 2012.

[11] Z. H. Li and Z. Z. Liu, "Study on monitoring dam deformation with GPS positioning," Journal of Wuhan University of Hydraulic and Electric Engineering, vol. 29, no. 6, pp. 26-29, 1996.

[12] C. D. Ince and M. Sahin, "Real-time deformation monitoring with GPS and Kalman filter," Earth, Planets and Space, vol. 52, no. 10, pp. 837-840, 2000.

[13] X. F. He, W. G. Sang, and D. Z. Jia, "Deformation monitoring of steep rock slopes by means of GPS," Journal of Hydraulic Engineering, vol. 37, no. 6, pp. 746-750, 2006.

[14] E. Gökalp and L. Taşçı, "Deformation monitoring by GPS at embankment dams and deformation analysis," Survey Review, vol. 41, no. 311, pp. 86-102, 2013.

[15] A. Lokke and A. K. Chopra, "Direct finite element method for nonlinear analysis of semi-unbounded dam-water-foundation rock systems," Earthquake Engineering \& Structural Dynamics, vol. 46, no. 8, pp. 1267-1285, 2017.

[16] Y. R. Liu, Q. Yang, and L. Zhu, "Abutment stability analysis of arch dam based on 3D nonlinear finite element method," Chinese Journal of Rock Mechanics and Engineering, vol. 27, no. s1, pp. 3222-3228, 2008.

[17] M. Zhou, B. Zhang, C. Peng, and W. Wu, "Three-dimensional numerical analysis of concrete-faced rockfill dam using dual-mortar finite element method with mixed tangential contact constraints," International Journal for Numerical and Analytical Methods in Geomechanics, vol. 40, no. 15, pp. 2100-2122, 2016.

[18] C. P. Zhang, D. L. Zhang, J. J. Luo, M. S. Wang, and J. P. Wu, "Remote monitoring system applied to the construction of metro station undercrossing existing metro tunnel," Rock and Soil Mechanics, vol. 30, no. 6, pp. 1861-1866, 2009.

[19] J. Bai, P. Lin, P. Li, and W. Zhou, "Reinforcement effects of Lijiaxia arch dam on complicated rock foundations and its back analysis," Chinese Journal of Rock Mechanics and Engineering, vol. 27, no. 5, pp. 902-912, 2008.

[20] T. F. Bao, C. S. Gu, and Z. R. Wu, "Analysis of uplift pressure anomaly of Lijiaxia Dam foundation," Chinese Journal of Geotechnical Engineering, vol. 30, no. 10, pp. 1460-1466, 2008.

[21] Y. H. Zhang, H. X. Li, Q. Sheng, K. Wu, Z. Y. Li, and Z. P. Yue, "Study of highway landslide monitoring and early warning based on surface displacements," Rock and Soil Mechanics, vol. 31, no. 11, pp. 3671-3677, 2010.

[22] K. Wu, Q. Sheng, Y. H. Zhang, Z. Y. Li, H. X. Li, and Z. P. Yue, "Development of real-time remote monitoring and forecasting system for geological disasters at subgrade slopes of mountainous highways and its application," Rock and Soil Mechanics, vol. 31, no. 11, pp. 3683-3687, 2010.

[23] Y. L. Zhang, S. L. Yang, X. Y. Luo et al., "BeiDou/GPS displacement detection using robust precise weighting based on moving window," Acta Geodaetica et Cartographica Sinica, vol. 45, no. S2, pp. 72-81, 2016.

[24] X. M. Song, X. J. Ye, X. Q. Zeng et al., "Study and improvement on equivalence classes of PostgreSQL query optimization," Computer Engineering and Applications, vol. 50, no. 14, pp. 31-38, 2014.

[25] C. Y. Chen, S. J. Wang, and X. K. Shen, "Predicting models to estimate stability of rock slope based on artificial neural net work," Chinese Journal of Geotechnical Engineering, vol. 23, no. 2, pp. 157-161, 2001.

[26] J. Q. Sun and H. B. Xu, "Fuzzy-neural network based on T-S model," Journal of Tsinghua University, vol. 37, no. 3, pp. 76-80, 1997.

[27] S. Y. Chen, Y. P. Zhu, and L. H. Huang, "Application of chaotic time series analysis to the prediction of tunnel surrounding rock displacement," Modern Tunnelling Technology, vol. 52, no. 3, pp. 75-81, 2015. 


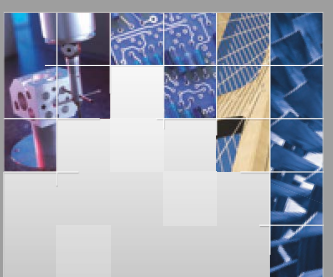

\section{Enfincering}
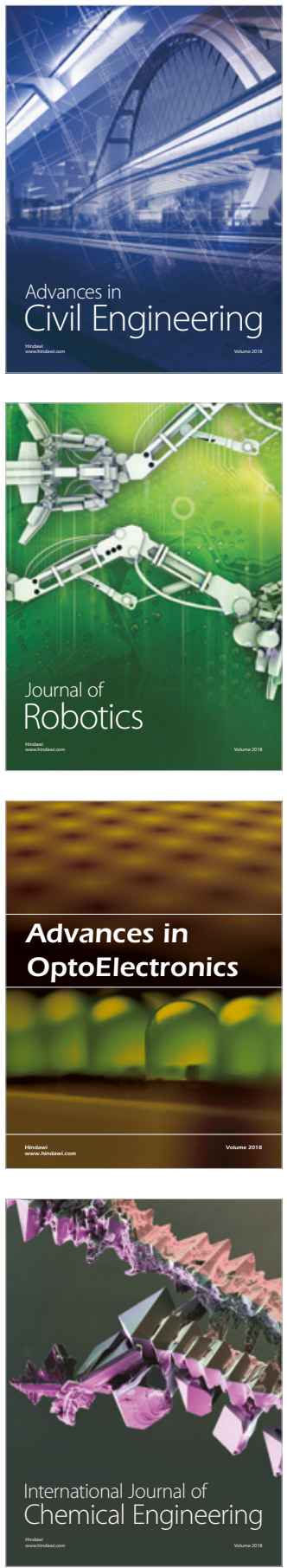

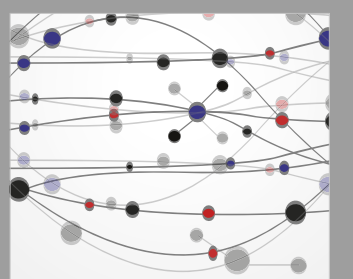

\section{Rotating \\ Machinery}

The Scientific World Journal

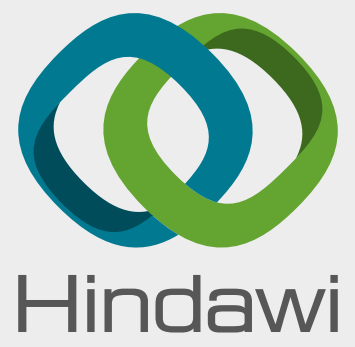

Submit your manuscripts at

www.hindawi.com
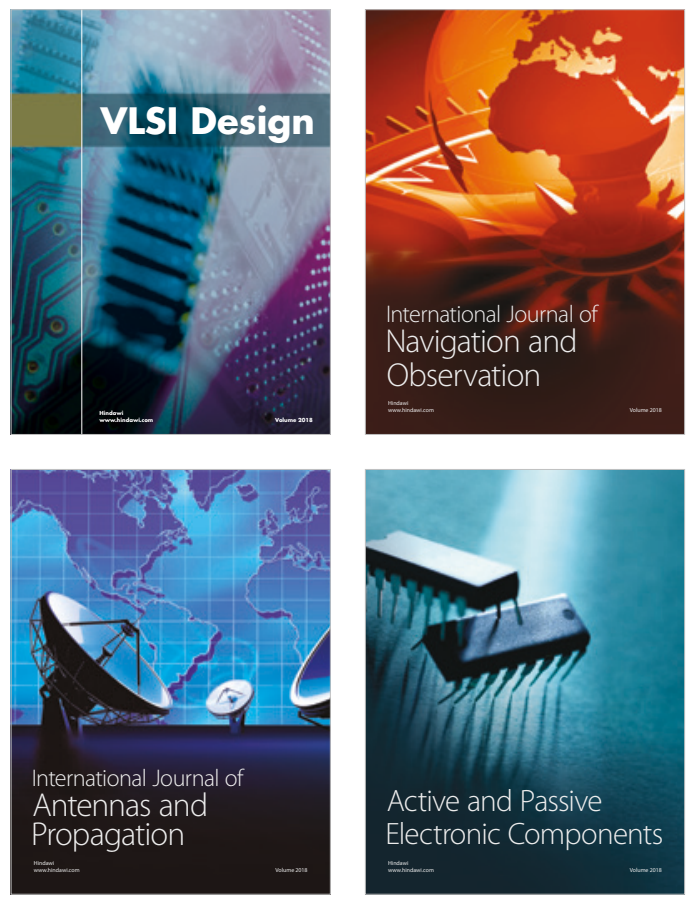
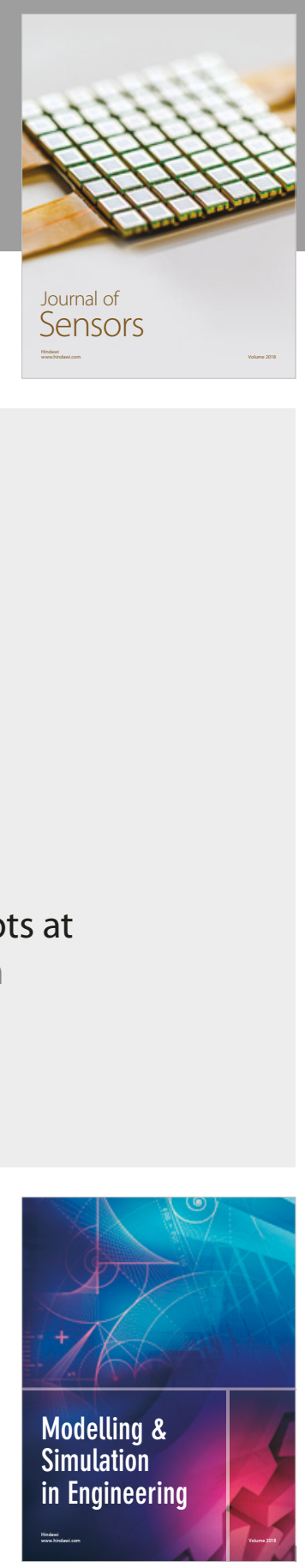

\section{Advances \\ Multimedia}
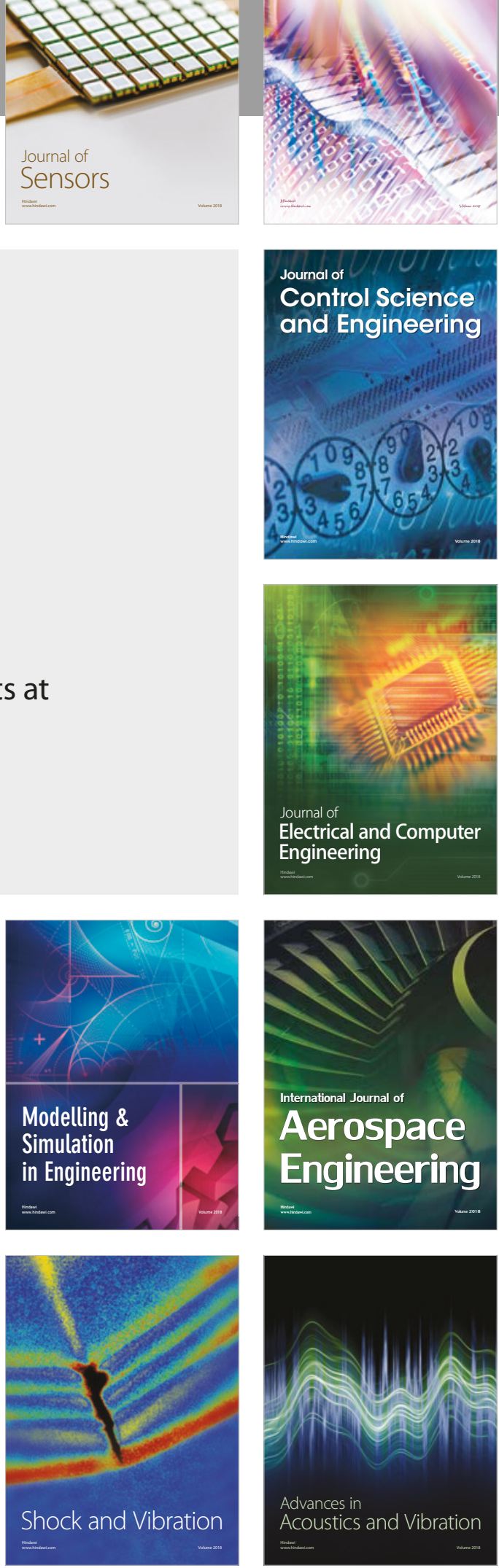